\title{
Personalized adaptive learning: an emerging pedagogical approach enabled by a smart learning environment
}

\author{
Hongchao Peng ${ }^{1 *}$, Shanshan $\mathrm{Ma}^{2}$ and Jonathan Michael Spector ${ }^{2}$
}

\author{
* Correspondence: hongchao5d@ \\ qq.com \\ ${ }^{1}$ Department of Education \\ Information Technology, Faculty of \\ Education, East China Normal \\ University, Shanghai, China \\ Full list of author information is \\ available at the end of the article
}

\begin{abstract}
Smart devices and intelligent technologies are enabling a smart learning environment to effectively promote the development of personalized learning and adaptive learning, in line with the trend of accelerating the integration of both. In this regard, we introduce a new teaching method enabled by a smart learning environment, which is a form of personalized adaptive learning. In order to clearly explain this approach, we have deeply analyzed its two pillars: personalized learning and adaptive learning. The core elements of personalized adaptive learning and its core concept are explored as well. The elements are four: individual characteristics, individual performance, personal development, and adaptive adjustment. And the core concept is referred to a technology-empowered effective pedagogy which can adaptively adjust teaching strategies timely based on real-time monitoring (enabled by smart technology) learners' differences and changes in individual characteristics, individual performance, and personal development. On this basis, A framework of personalized adaptive learning is also constructed. Besides, we further explored a recommendation model of the personalized learning path. To be specific, personalized adaptive learning could be constructed from the following four aspects, namely, learner profiles, competencybased progression, personal learning, and flexible learning environments. Last, we explored a form of learning profiles model and a generative paths recommendation pattern of personal learning. This paper provides a clear understanding of personalized adaptive learning and serves as an endeavor to contribute to future studies and practices.

Keywords: Smart learning environment, Data decision-making, Personalized learning, Adaptive learning, Man-machine collaboration, Learning paths recommendation
\end{abstract}

\section{Introduction}

The modern learning environment began with the "class-based teaching system" of Comenius. With the development of technology, technology-enhanced learning has gradually entered classrooms and experienced four changes (Adu and Poo 2014): a) elearning, b) m-learning, c) u-learning, and d) s-learning (Smart Learning). Against such background, the technology-enhanced learning environment has also evolved from an e-learning environment to a smart learning environment (SLE). As a high-end form of e-learning (Huang et al. 2012), SLE is built with two types of technologies: smart devices technologies (such as the Internet of Things, wearable devices) and intelligent technologies (such as learning analysis, cloud computing (Gros 2016). These two types

(c) The Author(s). 2019 Open Access This article is distributed under the terms of the Creative Commons Attribution 4.0 International License (http://creativecommons.org/licenses/by/4.0/), which permits unrestricted use, distribution, and reproduction in any medium, provided you give appropriate credit to the original author(s) and the source, provide a link to the Creative Commons license, and indicate if changes were made. 
of technologies enabled the smart learning environments to have features of tracking learning process, recognizing learning scenario, awareness of physical environment, connecting learning communities, adaptive function, and natural interaction (Huang et al. 2013; Zhu et al. 2016), which bring learners more flexibility, effectiveness, adaptation, engagement, motivation and feedback (Spector 2014). Therefore, SLE should be able to promote the development of personalized learning and adaptive learning effectively.

In fact, personalized learning and adaptive learning have always been the core goals of an SLE. Huang et al. (2013) defined SLE as a learning place or activity venue for promoting effective learning. Kinshuk mentioned that personalized learning and adaptive learning are two kinds of effective learning that SLE mainly focuses on in an interview (Yang et al. 2015). The development of current technologies has made personalized learning increasingly adaptive, adaptive learning increasingly personalized. Such a trend is much more obvious in smart technology-enabled SLE. A revised teaching method, personalized adaptive learning (PAL), will come along with this trend. The new personalized learning approach is automatic and uses decisions based on data gathered by an automated system; it accommodates learning to learners' real-time learning conditions and makes the learning content and activities meet learners' individual characteristics and needs. In this paper, we aim to explore the core concept of a new form of personalized learning and construct an appropriate framework in order to provide a reference for scholars to carry out follow-up research and educators to explore practical ways to implement personalized and adaptive learning in the age of automated learning support systems.

\section{Review: the development of personalized adaptive learning}

The emergence of personalized adaptive learning is due to the rise of big data technology, data is generated in more and more ways and faster and faster speed, which has spawned Data-Intensive Science, the fourth scientific research paradigm (Hey et al. 2009). Under the influence of data-intensive science, personalized adaptive learning has become the fifth-generation educational technology research paradigm (Zhu and Shen 2013). Based on big data, it has become an important part of a digital learning environment (Zhu and Guan 2013).

In fact, the wisdom of personalized learning can be traced back to Confucius's "teaching students according to their aptitude" and Socrates's elicitation teaching theory. After class teaching system became popular, it once entered a long trough. With "student-centered" becoming the core theory of teaching and learning, personalized learning has once again been sought after and has become a new goal of educational reform. Traditional personalized learning is mostly realized through special teaching systems and organizational forms, such as the ancient private school education (Wu 2015) and the current optional class system. The integration of technology has spawned a new development path: personalized learning empowered by technology.

The typical event of personalized technology-empowered personalized learning is the appearance of Skinner's teaching machine and program teaching theory (Wleklinski 2017). Since then, personalized learning has begun to have the characteristics of adaptability. Limited by the level of technology, the initial technology-empowered personalized learning, such as Computerized Adaptive Testing (CAT), is mainly based on simple rules or standards (Weiss and Kingsbury 1984). Its essence is just to transfer a 
student to somewhere of the predetermined learning route according to his/her feedback information. The accuracy and flexibility of it are very low. With the development of technology, personalized learning has gradually become more complicated. The typical representative is the Knewton platform. It differentiates and guides the continuous personalized learning process (Green-Lerman 2015) by knowledge maps and monitoring and responding to students' activities (communication, collaboration, and game) in real-time (Knewton 2017). But the personalized data of the Knewton platform mainly comes from the test answer record, and there is still a certain gap with the record of the whole process of learning (Wan and Wang 2016).

The rise of big data makes it possible to record and interpret students' individual characteristics and real-time state in all learning aspects. According to a briefing by the U.S. Department of Education, the application of big data in the field of education is mainly education data mining and learning analysis(U.S. Department of Education 2012). The collaboration of the two can promote the use of recorded learning data more effectively in assessing learning processes, predicting future performance and identifying potential problems (Zhu and Guan 2013). Based on this, Zhu's research team designed a personalized adaptive learning system with three feedback loops of data streams (Zhu and Shen 2013), which clearly outlines the structure and mechanism of personalized adaptive learning.

\section{Analysis: comparing the two pillars of personalized adaptive learning}

For the relationship between personalized learning, adaptive learning, and differentiated instruction, there are two current mainstream views: a) the inclusion relation of the former contains the latter, and b) the overlapped correlations of the three (like Venn diagram). The analysis of their multiple definitions reveals that both cases exist.

The differences and similarities between personalized learning and adaptive learning Personalized adaptive learning is formed by the combination of personalized learning and adaptive learning. A variety of past definitions are shown in Table 1. The left side of Table 1 is a list of definitions of personalized learning by the U.S. Department of Education, the British Educational Communications and Technology Agency, and a Chinese scholar Professor Li Kedong (the definition is recognized by many scholars in China). Although each of those definitions has its priority, three common core elements are highlighted, namely individual differences, personal needs and personal development (a.k.a. individual vision). These elements are confirmed by the International Association for K-12 Online Learning (INACOL 2016), the Department of Education and Skills (DfES 2006), Dreambox (n.d.), and the other studies by many scholars.

The first two lines on the right side of Table 1 is a list of definitions of adaptive learning by the New Media Alliance (NMC) and American Higher Education Informatization Association (EDUCAUSE). These two definitions are consistent with the mainstream view: regarding adaptive learning as a type of technology. This is because adaptive learning derives from artificial intelligence and is supported by intelligent technology. From the perspective of pedagogy, scholar John K. Waters portrayed the essence of adaptive learning: teaching methods enabled by technology (the third line on the right side of Table 1). Regardless of being as technology or teaching methods, the 
Table 1 Comparison between Personalized Learning and Adaptive Learning

\begin{tabular}{|c|c|}
\hline Personalized learning & Adaptive learning \\
\hline $\begin{array}{l}\text { Personalized learning refers to instruction in which the } \\
\text { pace of learning and the instructional approach are } \\
\text { optimized for the needs of each learner. Learning } \\
\text { objectives, instructional approaches, and instructional } \\
\text { content (and its sequencing) may all vary based on } \\
\text { learner needs. In addition, learning activities are } \\
\text { meaningful and relevant to learners, driven by their } \\
\text { interests, and often self-initiated. (U.S. Department of } \\
\text { Education, Office of Educational Technology 2017) }\end{array}$ & $\begin{array}{l}\text { Adaptive learning refers to the technologies monitoring } \\
\text { student progress, using data to modify instruction at } \\
\text { any time. (Adams Becker et al. 2017) }\end{array}$ \\
\hline $\begin{array}{l}\text { The pedagogy of personalising learning is learner- } \\
\text { centred. It is an inclusive process which challenges } \\
\text { those involved to meet the needs of all learners, } \\
\text { particularly those learners who are vulnerable or } \\
\text { hard to reach (BECTA 2007) }\end{array}$ & $\begin{array}{l}\text { Adaptive learning technologies dynamically adjust to } \\
\text { the level or type of course content based on an } \\
\text { individual's abilities or skill attainment, in ways that } \\
\text { accelerate a learner's performance with both automated } \\
\text { and instructor interventions (EDUCAUSE 2016) }\end{array}$ \\
\hline $\begin{array}{l}\text { Personalized learning refers to a learning paradigm that } \\
\text { aims at promoting students' individual development, } \\
\text { emphasizing that the learning process should adopt } \\
\text { appropriate teaching methods, techniques, content, } \\
\text { starting points, processes, and evaluation methods to } \\
\text { meet the individual characteristics and development } \\
\text { potential of students, so that all aspects of students } \\
\text { could be developed fully, freely and harmoniously } \\
\text { (Li 2015) }\end{array}$ & $\begin{array}{l}\text { Adaptive learning strategies create a student } \\
\text { experience that is modified based on a student's } \\
\text { performance and engagement with the course } \\
\text { materials. At its heart is an approach to instruction } \\
\text { that relies on technology and data about student } \\
\text { performance to adjust and respond with content and } \\
\text { methodologies that develop a pathway to the } \\
\text { student's mastery of a particular learning objective } \\
\text { (Waters 2014). }\end{array}$ \\
\hline $\begin{array}{l}\text { Core Elements: individual differences, personal needs, } \\
\text { personal development (vision) }\end{array}$ & $\begin{array}{l}\text { Core Elements: individual differences, individual } \\
\text { performance, adaptive adjustment }\end{array}$ \\
\hline
\end{tabular}

three elements are the same: individual differences, individual performance, and adaptive adjustment. In that sense, this revised form of personalized adaptive learning is not new. Rather, it builds of prior attempts to make learning more individually meaningful.

\section{The in-depth analysis of personalized learning, adaptive learning, and differentiated instruction}

Intuitively, both personalized learning and adaptive learning focus on individual differences which, mainly individual characteristics, is the purpose of differentiated instruction. The definition of the Association for Supervision and Curriculum Development (ASCD) is the interpretation of this purpose: differentiated instruction is a kind of instruction that educators actively plan for the differences of students so that all students can learn best. In a differentiated instruction classroom, teachers assign their time, resources, and energy to students with different backgrounds, preparations, skill levels, and interests to teach them effectively (ASCD 2018). According to the definition of the US Department of Education, in the differentiated instruction, all students have the same goal, but the teaching methods are different (U.S. Department of education, office of educational technology 2010). It is easy to make the conclusion that both personalized learning and adaptive learning contain the concept of differentiated instruction, which in the past has been reserved for special needs students.

Furtherly, the individual differences in personalized learning include two parts: individual characteristics and non-individual characteristics. The latter is actually one aspect of personal needs and personal development. According to the definition of personal needs, the gap between the current situation and the intended state of a learner, the difference of students needs is determined by the current state and the 
intended state. The former can be part of individual characteristics, and the latter can be attributed to personal development. In this way, the core elements of personalized learning can be refined into two aspects: individual characteristics and personal development. One new aspect of personalized adaptive learning is the recognition of individual learner interests and desires as relevant to education.

The above definitions of adaptive learning do not show it emphasizes the personal development of students. Therefore, individual differences in adaptive learning are mainly related to the differences in individual characteristics. Thus, the core elements of adaptive learning can be modified into individual characteristics, individual performance and adaptive adjustment. Comparing the new core elements of both learning methods, personalized learning does not mention the implementation strategies, but adaptive learning does (adaptive adjustment). A second new aspect of personalized adaptive learning is an emphasis on designs and implementations that in fact support individual development.

\section{Constructing the relational diagram among related learning methods}

It can be concluded from the above, there is no limit to the number of students for personalized learning, adaptive learning, and differentiated instruction. Therefore, they are not individualized instruction. However, the most dependent on high-end technology of adaptive learning, it is more concerned with the specific situation of each individual than the other two methods. In addition, from the perspective of personality, differentiated instruction, focusing on the difference of individual characteristics, has the lowest personalized level; adaptive learning comes second, it rises to the level of individual performance; personalized learning is the highest, reaching the pursuit of personal development. These are visually depicted in Fig. 1.

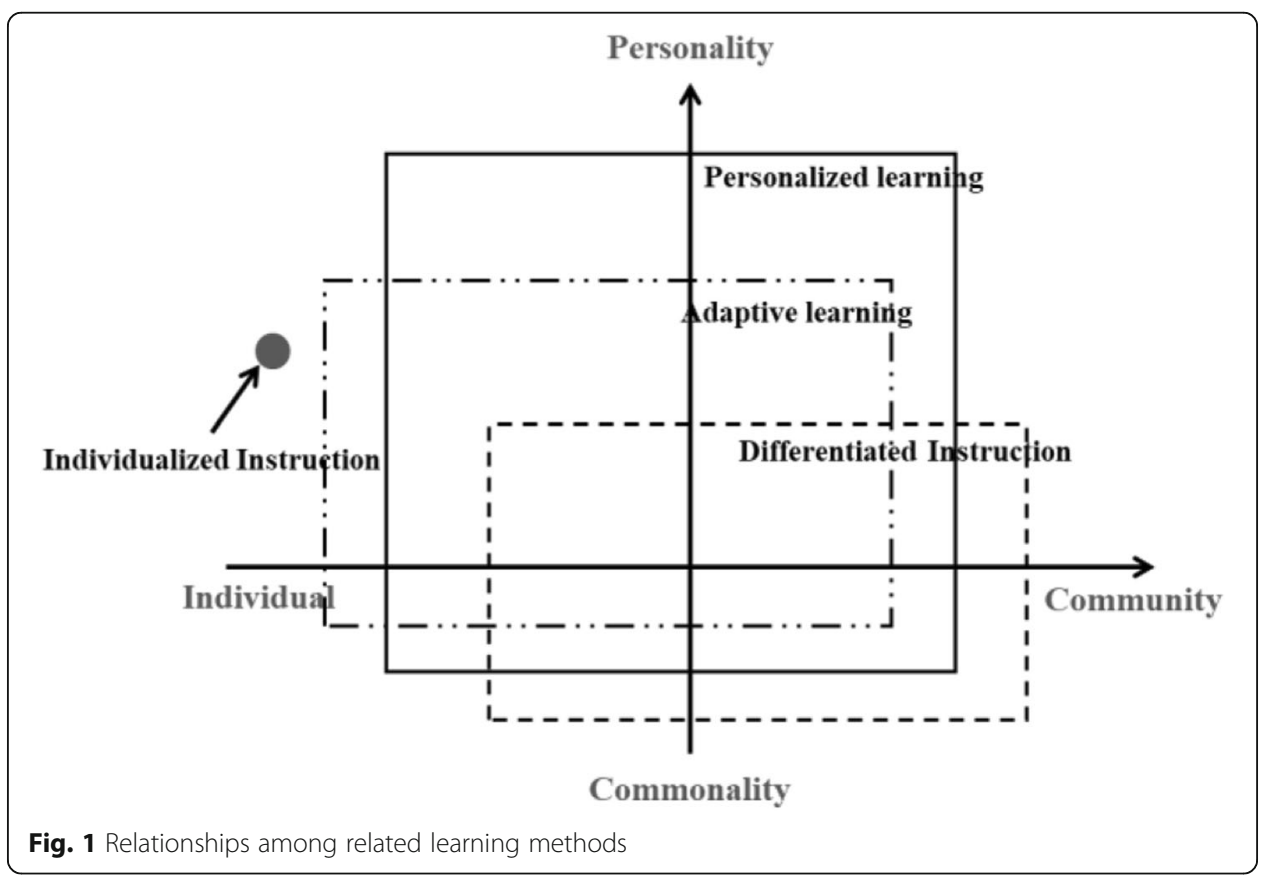


Core concepts: the values of personalized adaptive learning

Combining the core elements of personalized learning and adaptive learning, the core elements of personalized adaptive learning can also be proposed: individual characteristics, individual performance, personal development, and adaptive adjustment. The first three represent three personalized levels of personalized adaptive learning. The fourth indicates that adaptive adjustments strategy of teaching to achieve these three personalized levels. Like adaptive learning, this strategy is inseparable from the empowerment of technology. Based on these four elements, personalized adaptive learning can be defined as a technology-empowered effective pedagogy which can adaptively adjust teaching strategies timely based on real-time monitored (enabled by smart technology) learners' differences and changes in individual characteristics, individual performance, and personal development.

The assumption behind this core concept is the same as that of adaptive learning, namely, the appropriate is the best. Because each individual is different in all aspects and is in a state of constant change, it is necessary to personally monitor them in real time and adjust the teaching in an adaptive manner to ensure that the teaching strategy is always suitable for the individual student. In addition, this concept, like smart education, needs to adhere to the view that "technology promotes education rather than leads education" (Zhu et al. 2018). This is because, so far, few technologies were created for teaching, and the convenience pursued by technology is not what education seeks (Zhu and Wei 2018) which is the effectiveness of promoting human development.

\section{Framework: the portrait of personalized adaptive learning}

Based on the core elements and core concepts mentioned above, a framework of personalized adaptive learning is constructed. As shown in Fig. 2, the horizontal axis acts as an adaptation axis to characterize the current individual performance and the vertical axis is used as a personality axis to characterize the personal development. The two-axis intersection acts as individual characteristics to represent differentiated instruction shared by personalized learning and adaptive learning.

\section{Three approaches to achieve personalized adaptive learning}

There are three approaches to achieve personalized adaptive learning: 1) Adjust the teaching strategies based on the differences in individual characteristics (circular); based on the first approach, 2) adjust the teaching strategies combined with the differences and changes in current individual performance (horizontal ellipse); and 3) adjust the teaching strategies combined with the differences and changed in personal development vision (vertical ellipse). All three approaches can be implemented by adaptively adjusting teaching based on data-driven decision-making. Data-driven decision-making is the core hub of the framework.

The first approach is the upgrading of differentiated instruction strategies. The traditional differentiated instruction strategies are grouping: homogeneous grouping, heterogeneous grouping. Stratified teaching is a representative form of the solidified and roughly differentiated instruction. In the information technology environment, dynamic grouping and intervention have become possible. The second approach is based on the concept of adaptive learning. There are two main types of teaching strategies: rule- 


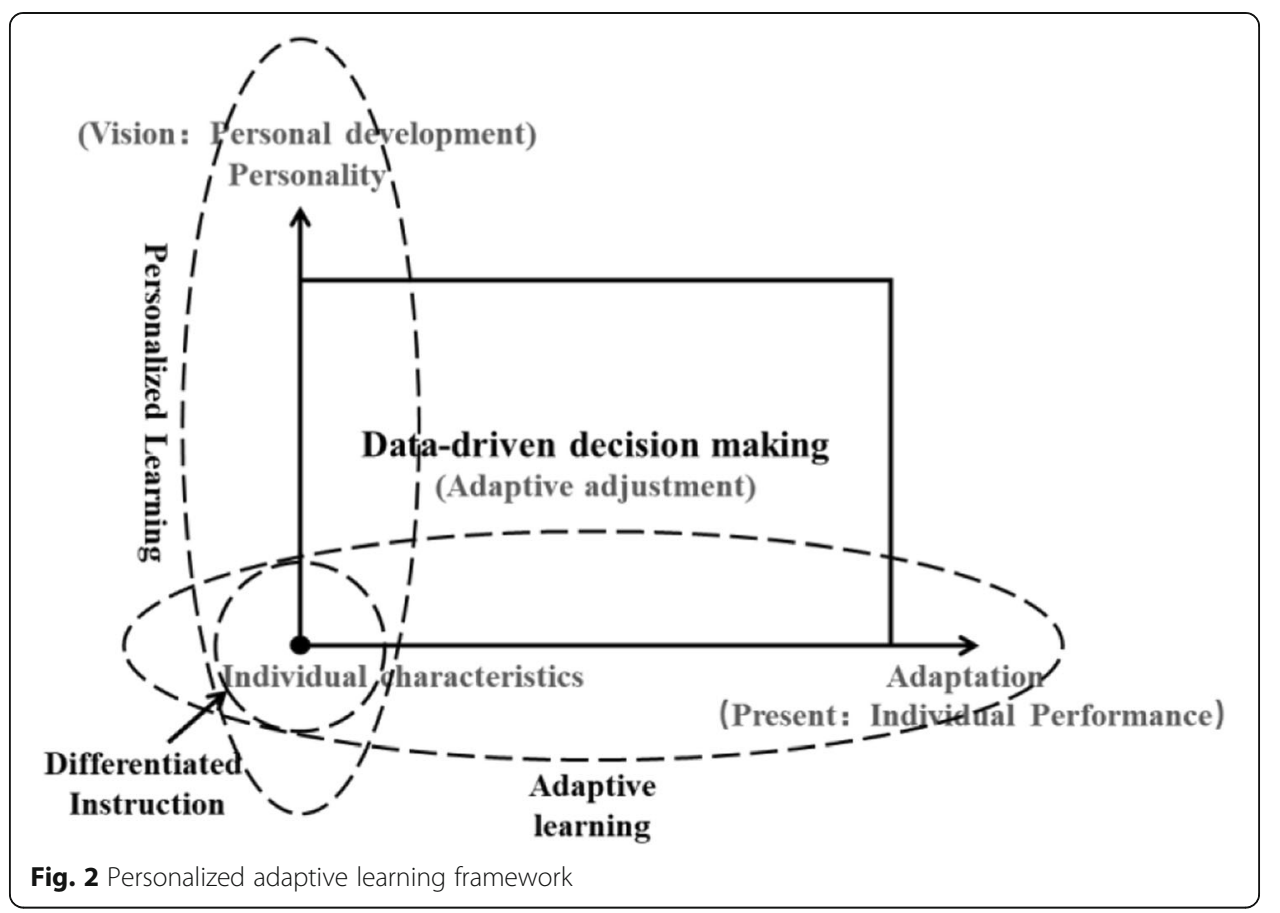

based or data-driven. The teaching strategy of the former is pre-predetermined according to the decision tree, and the teaching strategy of the latter is dynamically generated using student's data. The third approach is for personal development vision. The main strategy can be divided into three levels of strategies according to the granularity: program level, course level, and task level. The program level involves institutional changes, such as optional class system, elective system, and etc.; the course level involves the planning of the learning path; and the task level involves the adaptation of content, services, and etc. All of these three approaches can be implemented based on the adaptive adjustment of data-based teaching decisions. Therefore, data decision making is the core hub, see Fig. 2.

The forth approaches: adaptive adjustment instruction strategies

By using the three levels of personalized learning as the abscissa and the two types of data decision-making as the ordinate, six parts of adaptive adjustment instruction strategies can be divided by a two-dimensional coordinate system, a spectrum of these strategies is depicted, see Fig. 3. The wavy line in the figure represents the forth approaches route of personalized adaptive learning which starts from the bottom left towards the upper right.

The route is divided into three layers. They are individual characters layer, individual performance layer, and personal development layer. Each layer consists of two phases.

The individual characters layer mainly solves the problem related to "what to learn". The data-driven decision-making stage of this layer focus on resources recommend. Which mean machines recommend a resource list that matches the individual characteristics of the student who needs help, or a resource list learned by the successful learners who have similar individual characteristics with the student. The list is sorted according to the matching degree from high to low, and students can choose their 


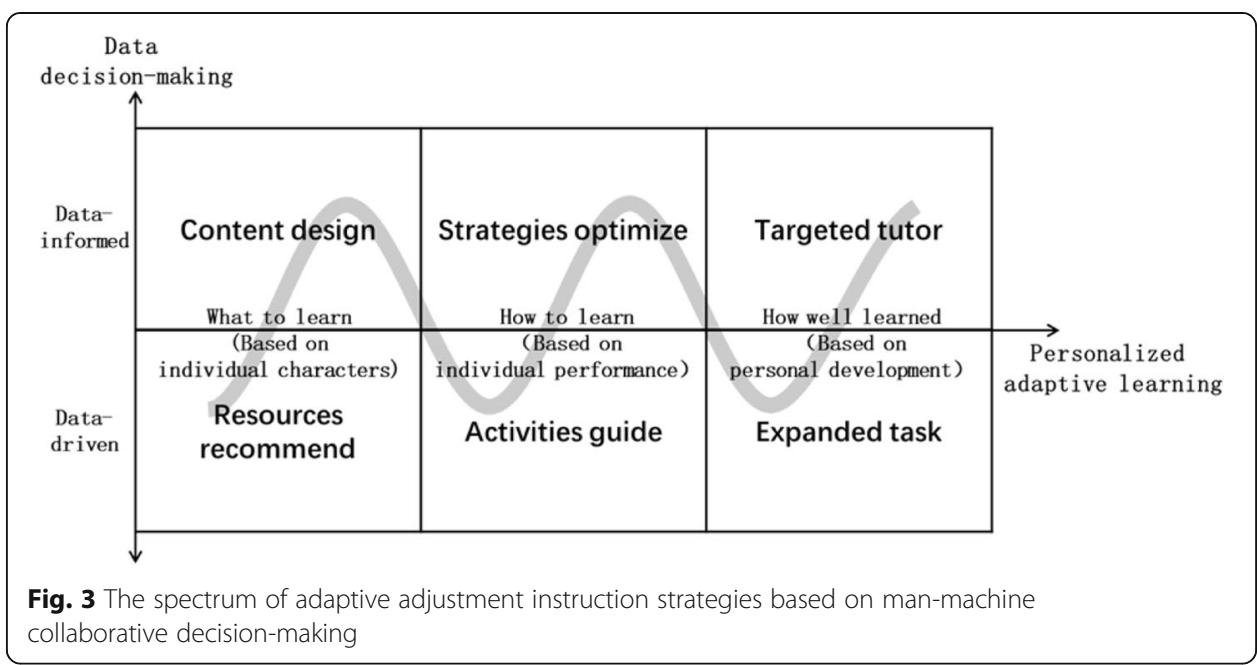

favorite resources to learn. The data-informed decision-making stage of this layer focuses on content design. Which means that teachers use agile design ideas to design learning content for learners whose individual characters failed to match that of others. The content is gradually optimized by multiple iterations and increments according to the differences and changes of learners' individual characteristics.

The individual performance layer addresses "how to learn" problem. The datadriven decision-making stage at this layer mainly focuses on activities guide. Which is to identify his/her learning pattern by analyzing students' performance data. If the pattern shows that the student has a problem and the problem is only an individual phenomenon, then it can be concluded that the problem comes from the student instead of teaching strategies. Therefore, the student's activities need to be adjusted. If the problem is a problem that happens to the majority, then it can be concluded that there is a high possibility that the teaching strategies need to be optimized. This process occurs in the stage of data-informed decision-making of this layer.

The personal development layer addresses the issue of "how well learned" for their personal vision. The data-driven decision-making stage of this layer predicts whether students can complete the learning objectives ahead of time by monitoring the learning achievements (for specific instruction, please refer to measuring to assist learning mechanism of precision teaching), and the answer is yes, then more challenging expanded tasks that meet their personal vision would be recommended. The datainformed decision-making stage of the layer focuses on the problems that students encounter when they are doing challenging expanded tasks. Which is to use a centralized tutoring method for the same problems encountered by the majority, and to provide individual tutoring methods for the problems encountered by individuals.

The new approaches route provides personalized adaptive learning services for learners in terms of the degree of personalization, and it can be well compatible and integrated with differentiated instruction, adaptive learning, and personalized learning. Therefore, this route sheds a light on the path for technology developers to achieve personalized adaptive learning based on the original informatization achievements. 
Implementation: the starting point of constructing personalized adaptive learning

For constructing personalized adaptive learning, we think the following efforts should be made: monitoring learners' differences and changes in individual characteristics, individual performance, personal development, and adapting teaching strategies. Which provides a work direction of personalized adaptive learning that is extremely consistent with four attributes of personalized learning proposed by Bill \& Melinda Gates Foundation: learner profiles, competency-based progression, personal learning, and flexible learning environments (K-12 Education Team 2014).

Learner profiles aim to portray the individual characteristics of each learner's strengths, preferences, motivations, etc.; competency-based progression evaluates the learner's progress by continuously measuring the individual performance of the learner's learning objectives; personal learning is to provide a learner with a path to personal development; flexible learning environment as a flexible and intelligent learning environment can provide functional support for the adaptive adjustment of teaching strategies.

Among these four attributes, building a flexible learning environment is the basic premise of the others. Fortunately, since IBM released the "Smart Earth" strategy, many countries have actively taken their actions (Palmisano 2008). In the following section, learning portrait model and paths recommendation pattern of personal learning are explored.

\section{Learning portrait model}

Learning portrait model is a learning sequence composed of learning cells, it depicts the processes of the occurrence and development of learning. Exploring the learner's potential learning patterns with techniques such as educational data mining and machine learning is the key to achieving the recommendations of a personal learning path. Currently, learning path recommendations has shifted from focusing on in individuals' characteristics of learners, such as learning preferences and cognitive styles, to focusing on learning process and learning patterns. Considering this issue, a new learning portrait model is proposed to solve the problem of the precisive recommendation of personal learning path from a new perspective.

As shown in Fig. 4, the learning portrait model includes a learning cells sequence and a learning time sequence. The cells sequence, also called the learning pattern, is a directed graph which its nodes are composed of learning cells. The time in the node of the learning sequence represents the effective learing time spent on one learning cell and the time on the side represents the time interval in which the learner starts a new cell for the last one. The former time can reflect the degree of learning engagement. The longer this time, the bigger engagement the learner has in a certain part of the learning content. The time interval can reflect the learner's learning motivation. The smaller this time, the stronger the learning motivation. Therefore, the learning cell is an important element in learning portraits. The internal structure of the learning cell is shown in Fig. 5. The learning cell depicts the learner's micro-learning situation, which consists of three parts: learning content, learning activities and learning effects.

Learning content is to solve the problem of "what to learn", and it includes materials for learning, materials for practices and materials for creation (Anderson et al. 2001). Based on Bloom's taxonomy of cognitive goals, a hierarchical structure of learning content was constructed, as shown in Fig. 6. 


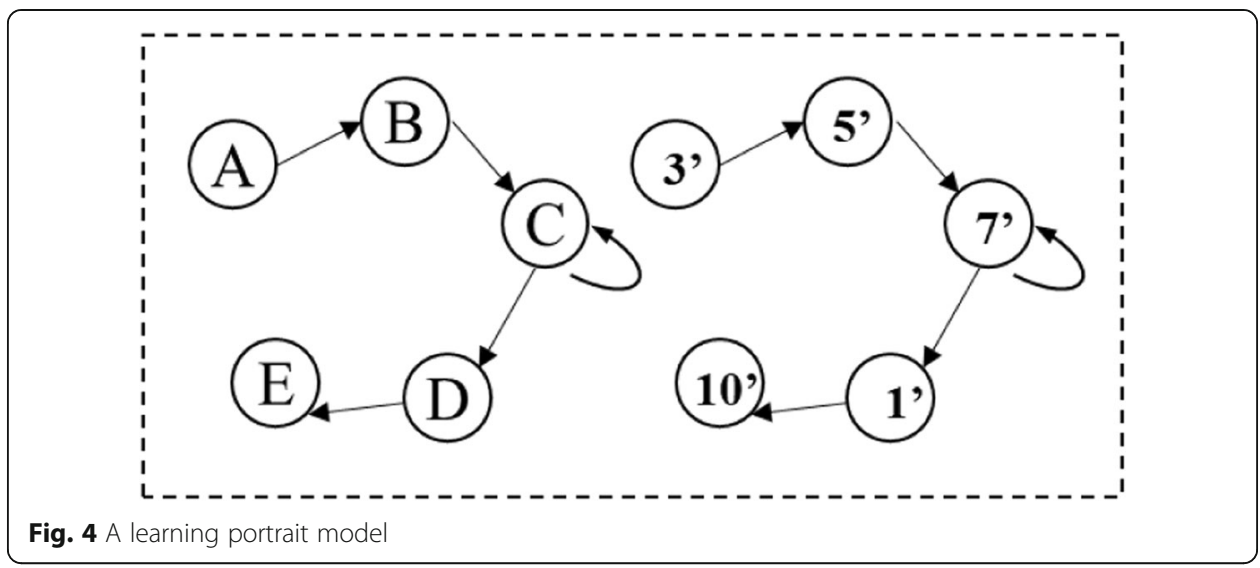

The materials for learning are at the lower level, that is the remembering and understanding level. This kind of materials includes various multimedia learning resources related to the learning content, such as text, video and audio, animation, etc.. The materials for practices, at the level of "apply" and "analyze", are for consolidating and internalizing learning content. It includes problem sets and tool kits, etc. Materials for creation are used for the transfer of learning content. They are at the level of "evaluate" and "create" and mainly include virtual experiments, simulation scenarios, cases, and the software or hardware of design and development.

Learning activities are aimed at addressing "how to learn." According to the activity theory (Sun and Liu 2015). Activities can be divided into three levels hierarchy: activities, actions, and operations. The learning activity can be seen as a sequence of learning

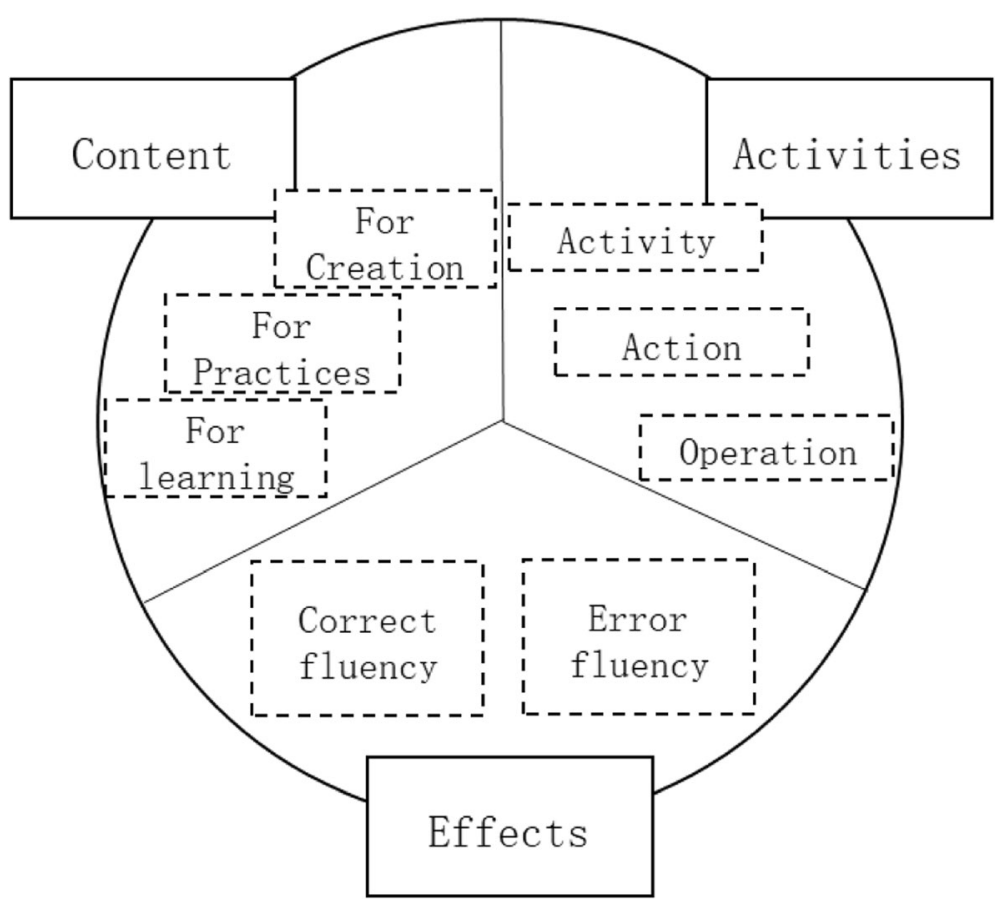

Fig. 5 The internal structure of a learning cell 


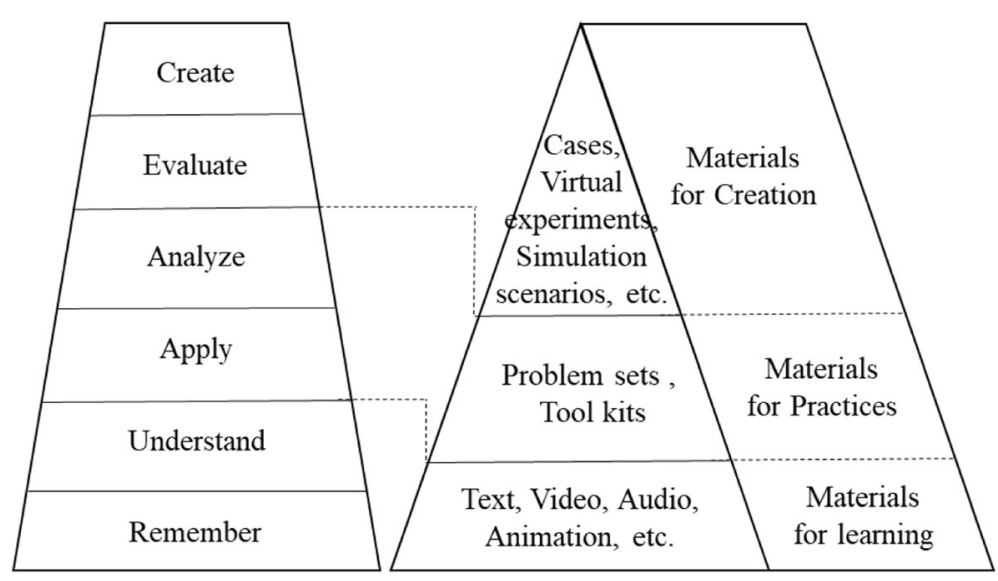

Fig. 6 The hierarchical structure of learning content

behaviors. Due to the differences in individual characteristics such as the learner's learning style and knowledge level, the learning activities are also different.

Learning effects refer to the learning outcomes after the learner completes a learning activity. For measuring the learning outcomes, fluency is used as the measurement index instead of traditional test score (Binder 1988), it can reflect the accuracy and speed of the learner's test (Peng and Zhu 2017). Therefore, fluency can better represent the learner's true learning effect. Fluency consists of correct fluency and error fluency, which is the correct or incorrect test score divided by the time it takes. By introducing the test time dimension, the efficiency of fluency can be greatly improved. For example, the learner took less time can be marked better by fluency than the one who has the same score but took more time.

\section{The generative paths recommendation pattern}

Previous studies define learning path as the sequences of activities and concept selected by the learners in the learning process (Kardan et al. 2014). In this study, a learning path is defined as a learning sequence composed of learning cells. In the following section, we will discuss the path recommendation process, the learning portrait matching strategies, and related algorithms.

\section{The flow of paths recommendation}

The flow of paths recommendation is shown in Fig. 7. The system uses different matching strategies to recommend a learning cells list according to the learner's learning state, and the learner can select the most suitable one to learn according to himself/herself needs., and then the system measures the learning effect, then generating the learner's learning profile. This is a process of continuously iterative generation; It allows the learner to have the autonomy of learning, instead of forcibly recommending the learning content, which highlights the initiative and subjectivity of the learner.

The learning path generation recommendation model has three important features: precision, personalization, and generativity. Precision is mainly reflected in two aspects: 1) the recommendation pattern divides learners into three categories, namely, class $A$ learners, class B learners, and class C learners, and adopts personalized matching 


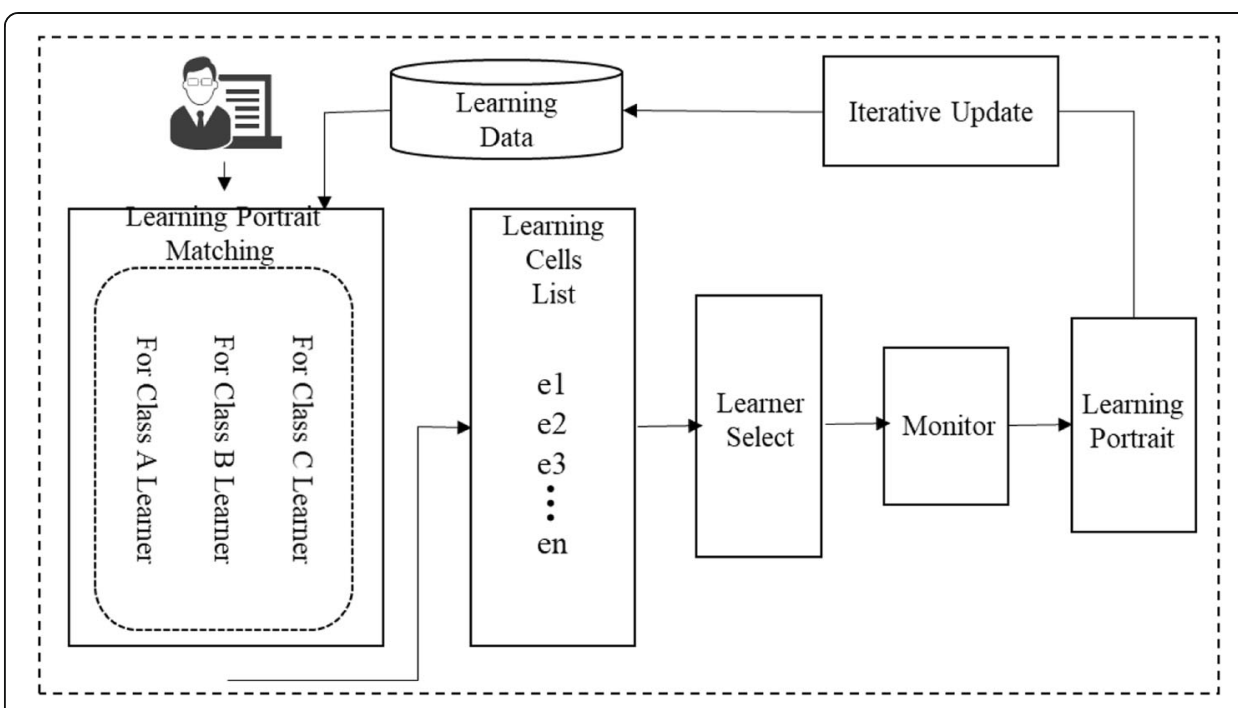

Fig. 7 The flow of the generative paths recommendation

strategies for different categories of learners; 2) the recommendation pattern matches the learner's learning profile to the best learner, and then recommends his/her learning cell to the target learner. Personalization is embodied in the recommendation strategy of learning list, that is, recommending a prioritized learning list to a learner for giving the learner opportunity to select one of his/her favorite or most suitable learning cell. This can fully reflect the initiative and subjectivity of the learner. Generativity refers to the system is not to recommend a complete learning path at a time, but to recommend one learning cell, and then next learning cell according to the learner's updated learning portrait until a complete learning path is recommended. Generativity fits the dynamics of learning levels and helps to improve the accuracy of recommendations.

\section{Diversified pattern matching}

The most critical step in the learning path generative recommendation is the matching of learning portraits. we divide learning portrait matching into three situations according to the learner's learning state: for class A learner matching, for class B learner matching, and for class $\mathrm{C}$ learner matching.

Class A learner refers to a learner who has no or very little recorded learning data. For this kind of learner, we should match him with the excellent learner who has successfully learned the learning content which Class A learner will learn so that system can recommend the matched learner's learning cell to class A leaner.

Class B learner matching is for a learner with a certain amount of learning data. In this situation, we suggest system math the learning cell of class B with other successful learner's. Recommend the most similar learning cell of a successful learner will work.

Class $\mathrm{C}$ learner matching is for the learner with a large amount of learning profile data. The system can first math the learning pattern of class $C$ learner with other successful learner's. Select the next learning cell in the successful learner's pattern to class C learner is the optimal solution. 


\section{Conclusions}

By interpreting SLE, we found that it has a large potential to effectively promote the development of personalized learning and adaptive learning, accelerating the fusion of these two learning methods (Hey et al. 2009; Zhu and Shen 2013). In this paper, the concept of personalized adaptive learning is proposed and used as a new pedagogical approach enabled by SLE. Additionally, the core elements and core concepts of personalized adaptive learning were presented through the comparative analysis between personalized learning and adaptive learning, and a framework of personalized adaptive learning was thus constructed in a visualized format. Finally, personalized adaptive learning could be constructed with the following four aspects, that is, learner profiles, competency-based progression, personal learning, and flexible learning environments. We hope that such research could present our readers a clear understanding of personalized adaptive learning, and provide a reference for the future relevant research and practices.

Acknowledgements

Not applicable.

Authors' contributions

All authors read and approved the final manuscript.

Funding

This paper was funded by the State Scholarship Fund of China Scholarship Council.

Availability of data and materials

Not applicable.

Competing interests

The authors declare that they have no competing interests.

\section{Author details}

${ }^{1}$ Department of Education Information Technology, Faculty of Education, East China Normal University, Shanghai, China. ${ }^{2}$ Learning Technologies, College of Information, University of North Texas, Denton, Texas, USA.

Received: 14 June 2019 Accepted: 6 September 2019

Published online: 18 September 2019

References

S. Adams Becker, M. Cummins, A. Davis, A. Freeman, C. Hall Giesinger, V. Ananthanarayanan, NMC Horizon Report: 2017 Higher Education Edition (The New Media Consortium, Austin, 2017)

E. K. Adu, \& D. C. C. Poo (2014). Smart Learning: A New Paradigm of Learning in the Smart Age. http://www.cdtl.nus.edu.sg/ Tlhe/tlhe2014/abstracts/aduek.pdf. Accessed 01 June 2019

L.W. Anderson, D.R. Krathwohl, B.S. Bloom, A Taxonomy for Learning, Teaching, and Assessing: A Revision of Bloom's Taxonomy of Educational Objectives: Allyn \& Bacon (2001)

ASCD. (2018). Differentiated Instruction. http://www.ascd.org/research-a-topic/differentiated-instruction-resources.aspx. Accessed 01 June 2019

BECTA. (2007). Personalising Learning: The Opportunities Offered by Technology. http://archive.teachfind.com/becta/ feandskills.becta.org.uk/display806e.html?resID=31571. Accessed 01 June 2019

C. Binder, Precision teaching: Measuring and attaining exemplary academic achievement. Youth Policy 10(7), 12-15 (1988)

DfES.(2006).2020 Vision: Report of the Teaching and Learning in 2020 Review Group. https://dera.ioe.ac.uk/6347/1/6856-DfESTeaching\%20and\%20Learning.pdf. Accessed 01 June 2019

Dreambox. (n.d.) Personalized Learning. http://www.dreambox.com/personalized-learning. Accessed 01 June 2019

EDUCAUSE. (2016). Adaptive Learning Systems: Surviving the Storm. https://er.educause.edu/articles/2016/10/adaptivelearning-systems-surviving-the-storm. Accessed 01 June 2019

Green-Lerman, H. (2015). Visualizing Personalized Learning. https://www.knewton.com/resources/blog/adaptive-learning/ visualizing-personalized-learning/. Accessed 01 June 2019

B. Gros, The design of smart educational environments. Smart. Learn. Environ. 3(1), 15 (2016)

T. Hey, S. Tansley, K. Tolle, The Fourth Paradigm: Data-Intensive Scientific Discovery (Microsoft research, Redmond, 2009)

R. Huang, J. Yang, Y. Hu, From digital to smart: The evolution and trends of learning environment. Open Educ. Res. 18(1), 7584 (2012)

R. Huang, J. Yang, L. Zheng, The components and functions of smart learning environments for easy, engaged and effective learning. Int. J. Educ. Med. Technol. 7(1), 4-14 (2013)

INACOL. (2016). What Is Personalized Learning?. http://www.inacol.org/news/what-is-personalized-learning/. Accessed 1 June 2019

K-12 Education Team. (2014). Early Progress: Interim Research on Personalized Learning. http://k12education.gatesfoundation. org/resource/early-progress-interim-research-on-personalized-learning/. Accessed 1 June 2019 
A.A. Kardan, M.A. Ebrahim, M.B. Imani, A new personalized learning path generation method: ACO-map. Indian J. Sci. Res. $5(1), 17(2014)$

Knewton. (2017). Knewton Adaptive Learning: Building the world's most Powerful Education Recommendation Engine. https://www.knewton.com/wp-content/uploads/knewton-adaptive-learning-whitepaper.pdf. Accessed 01 June 2019

K. D. Li (2015). Personalized Learning in E-Learning Environment. http://www.docin.com/p-1199857000.html. Accessed 01 June 2019

S. J. Palmisano (2008). A smarter Planet: The Next Leadership Agenda. https://www.ibm.com/ibm/cioleadershipexchange/us/ en/pdfs/SJP_Smarter_Planet.pdf. Accessed 01 June 2019

H.C. Peng, Z.T. Zhu, Measuring to assist learning: A Core mechanism of precision instruction in smarter education. E-Educ. Res. (3), 94-103 (2017)

J.M. Spector, Conceptualizing the emerging field of smart learning environments. Smart. Learn. Environ. 1(1), 2 (2014)

H.M. Sun, P.F. Liu, Learning activity in view of activity theory. China. Educ. Technol. 8, 29-35 (2015)

U.S. Department of Education, Office of Educational Technology Enhancing Teaching and Learning through Educational Data Mining and Learning Analytics: An Issue Brief (Washington, D.C, 2012)

U.S. Department of education, Office of Educational Technology, Transforming American Education: Learning Powered by Technology (Washington, D.C, 2010)

U.S. Department of Education, Office of Educational Technology, Reimagining the Role of Technology in Education: 2017 National Education Technology Plan Update (Washington, D.C, 2017)

H.P. Wan, D. Wang, Investigation on adaptive learning mechanism of big data based on Knewton platform. Mod. Educ Technol. 26(5), 5-11 (2016)

J. K. Waters (2014). The Great Adaptive Learning Experiment. https://campustechnology.com/articles/2014/04/16/the-greatadaptive-learning-experiment.aspx. Accessed 01 June 2019

D.J. Weiss, G.G. Kingsbury, Application of computerized adaptive testing to educational problems. J. Educ. Meas. 21(4), 361375 (1984)

N. Wleklinski (2017). Skinner's Teaching Machine and Programmed Learning Theory. http://people.ischool.illinois.edu/ chip/ projects/timeline/1954teaching_machine.html. Accessed 01 June 2019

G. Wu, Personalized education in globalization era. Nanjing J. Soc. Sci. (7), 104-110 (2015)

J. Yang, C. Hong, H. Yu, Kinshuk, Research focuses and trend on smart learning environments---Dialogue with ET\&S editor Kinshuk. E-Educ. Res. 36(5), 85-88 (2015)

Z.T. Zhu, J.Q. Guan, The construction framework of "Network Learning Space for Everyone". China. Educ. Technol. (10), 1-7 (2013)

Z.T. Zhu, H.C. Peng, Y.H. Li, Intelligence education: An approaches to smarter education. Open Educ. Res. 24(4), 13-24 (2018)

Z.T. Zhu, D.M. Shen, New paradigm of educational technology research based on Big Data. E-Educ. Res. (10), 5-13 (2013)

Z.T. Zhu, F. Wei, Educational Informatization 2.0: Starting on a journey of intelligence education guided by Smart Education. E-Educ. Res. 9, 5-16 (2018)

Z.T. Zhu, M.-H. Yu, P. Riezebos, A research framework of smart education. Smart. Learn. Environ. 3(1), 1-17 (2016)

\section{Publisher's Note}

Springer Nature remains neutral with regard to jurisdictional claims in published maps and institutional affiliations.

\section{Submit your manuscript to a SpringerOpen ${ }^{\circ}$ journal and benefit from:}

- Convenient online submission

- Rigorous peer review

- Open access: articles freely available online

- High visibility within the field

- Retaining the copyright to your article

Submit your next manuscript at $\boldsymbol{\nabla}$ springeropen.com 